neighborhood of the bird, and that one thought exerts a different influence upon the mental mechanism of worm than will another thought. These things we know; the only thing we do not know, and can not very well prove by practical experiment, is that the worm is able prove by practical experiment, is that the worm is

to utilize that influence in the way I have suggested.
If a man could live a million years and experimen If a man could live a million years and experiment
with birds and worms and butterflies, as Darwin experimented with doves and other animals to prove his theory of natural selection, we might prove our theory of the cause of mimicry to the extent of showing tha certain animals do assume the guise of other animals, or mimic them, for purposes of self-protection against their enemies, but we should not know then any better than we now know that the change was produced in the manner I have suggested. Although this conclusion manner I have suggested. Although this conclusion a rational theory, and one which should be accepted as most likely to account for the strange phenomena of mimicry in lower animals.

There are many well-authenticated instances which strongly tend to warrant the conclusion that certain lower animals possess peculiar psychic powers not usually the bent of mind of human creatures in whose presence the bent of mind

Many a time, when the owner of a dog has determined
they happen to be. to kill the $\operatorname{dog}$ in order to get rid of him for some reason or other, the dog immediately seems to discover the fact that there is some evil purpose brewing for him, and he will of ten slink away and hide without any apparent
cause. Of course, the voice of the master in calling the dog may change, and the dog will discover a sinister meaning in the difference of the voice, or the master's countenance may change, that is to say the master may manifest in his face his intentions regarding the dog. manifest in his face his intentions regarding the dog. no opportunity for the log to tell by the change in his master's demeanor or change of voice, and he has seemed to gather a warning directly from the operations of his master's mind.

I admit that there may never have been a single instance in authentic proof of this conclusion, but there have been instances enough to lead to a strong suspicion that the mind of a dog may be in such receptive telethat the mind of a $\log$ may be in such receptive tele-
pathic attitude with respect to the mind of his master pathic attitude with respect to the mind of his master
as to interpret the bent of his master's thoughts concerning the dog's welfare; and the dog's welfare is the principal thing that can concern the

In arriving at such conclusions as these, it is necessary for us to be strongly on our guard and to maintain alert vigilance against being humbugged by the deceit of others or by our own sentiments and imagination.

When we desire a thing, it is much easier to believe that thing than when we do not desire it. In spiritualistic investigations, this human peculiarity has given the wildest fancies the guise of scientific evidence.

In the interpretation of any natural phenomenon, we must not take our lack of ability to understand its having been produced in any other way as proof that it must have been produced in a certain hypothetical way. This we must admit applies to my suggestion of the explanation of mimicry in animals. We have not sufficient evidence to know whether this hypothesis is true or not, only enough to know that it is both possible and rational and based upon the broad foundation in fact that nothing can exist except under the domination of the universal influence of all things else, of which influence it is a sensitized reciprocal part; and that there must be a mutual influence exerted between the mental mechanism of lower animals existing in the neighborhood of one another. We further know that those animals have developed on the lines of their chief necessities; that, consequently, they are capable of utilizing any influence to meet their necessities.

Therefore, may we not conclude that it is reasonable to believe that hunted animals must have used any influence exerted upon them by hunting animals in the development of mimicry for defense, if that mimicry has been a necessity?

\section{The Use of Titanium in Steel Castings*} By W. A. Janssen

Notwithstanding all that has been said concerning the harmful effects of phosphorus and sulphur in steel, the occluded oxides and gases, such as iron oxide, $\mathrm{Fe}_{2} \mathrm{O}_{3}$, and an undefinable oxide, probably $\mathrm{FeO}$, free oxygen, nitrogen and occluded slags are the real causes of many of the troubles of the steel-maker. It is with the occurrence of these elements and their elimination that he is especially concerned. It has been definitely demonstrated that the presence of oxygen, and possibly nitrogen, in
steel reduces its static strength, dynamic properties and *From a paper presented at a Convention of the American
I oundrymen. From a report in The Iron Age. abrasive values and increases its tendency to corrode. Today the presence of oxygen and oxides in steel is considered more harmful than even relatively large amounts of phosphorus and sulphur. In a measure the same is true of nitrogen, although the investigations in this true of nitrogen, although the investigations in this
direction have not been sufficiently complete and the direction have not been sufficien
results are variable and uncertain.

With the advent of ferroalloys of silicon and manganese containing high percentages of the active elements came the hope of an assured uniform quality of stecl. As deoxidizers, modern ferroalloys are efficient in a measure, but have certain limitations. It is the function of these deoxidizers to combine with the occluded oxides; the resulting products rise and become a part of the slag. Unfortunately the temperature of the metal and its resultant fluidity do not always permit these to complete their cycle and rise to the slag; they are entrapped as inclusions and the occluded gases are not
entirely deoxidized. The known presence of oxides in excess of the amount which can be deoxidized by the usual additions of ferrosilicon and ferromanganese is not permitted because of specification tolerances for manganese and silicon content.

Silicon, comparatively speaking, is not a strong deoxidizer, and when it is added to steel a portion of it remains in the steel either as an alloyed constituent, or the products of its oxidation may remain as inclusions. The usual analyses for silicon do not disclose whether or not the silicon is present in the steel as an alloyed silicide, as silica or as the silicate. Even if the silicon manifest itself as a silicide, showing a high silicide percentage, a wild heat is apt to result, requiring the use of a further deoxidizer (aluminum) when pouring the molds. In manganese frequently are formed. Such a constituent manganese frequently are formed. Such a constituent
may contribute to excessive segregation, although may contribute to excessive segregation, although
singularly, a dirty steel often discloses very little segregation

Titanium, until a comparatively few years ago looked upon as one of the rare metals, undoubtedly is one of the most powerful deoxidizers and denitrogenizers of the ferroalloys. Its chief value lies in its positive action in the removal of the occluded oxides, nitrogen and entrapped slags, due to the fusibility of titanic oxide as formed and its greater stability as compared oxide as formed and its greater stability as compared
with iron oxide. Its function is further augmented by the increased fluidity due to the increased temperature because of the exothermic reaction, thereby permitting freer movements of the oxidized products to slag.

The present-day method of using ferrotitanium is to augment the incompleted cycle with ferrotitanium after the other deoxidizers have been added. These may be added in the ladle, or in the furnace before may be added in the ladle, or in the furnace before
tapping. After the titanium has been added, it is imperative and essential that the ladle be held from 5 to 10 minutes before pouring in order to allow time for the completion of the reactions. No fear need be had of the chilling of the metal inasmuch as the temperature is raised appreciably, due to the exothermic reaction. It is essential that the titanium be not added until after the additions of ferrosilicon and ferromanganese have been made. On account of the greater affinity it had been tried in England, and even before it was well under way. England has the honor of starting both the acid and the basic Bessemer, but it was left to the United States to show the world what an acid vessel could do, while Westphalia was to develop the possibilities of the basic converter. It is rather hard to explain just how this all came about, but the facts are clear.

Looking for a moment at the acid Bessemer in our own country, we know that from the beginning aimost every works made from two to five times as much stecl as the best plants across the water. For many years Europeans refused to believe that we told the truth about our output, and even a personal visit by some of their metallurgists would not convince them that operations could be carried on every day continuously under whip and spur. In the late ninetics, however, English plant that desired to increase its output installed American equipment in its Bessemer department. Any of our foremen, with a nucleus of American workAny of our foremen, with a nucleus of American work
men, could have doubled the tonnage in two months, men, could have doubled the tonnage in two months,
but the British steel workers refused to wake up, and it was necessary to build a second plant and run both of them at what we would call half speed.

The Germans have done for the basic Bessemer just he did for the acid converter; but they have not is so common in this country, because in a basic plant there are so many little things to watch all the time and so many extra operations. The adding of the lime, the decantation of the slag and the delay that secms to be necessary after the addition of the recarburizer, all make for slower work, while, as already stated, the converte lining has a shorter life. Under these conditions it is a
notable achievement when a plant of three 20-ton converters turns out 35,000 tons of steel in a month.

There are also technical problems at every step, for variation in the proportion of silicon in the pig iron will mean a change in the weight of lime added; again, any variation in the speed of the blowing engine makes a differcisce in the length of the overblow, while there is no sharp warning corresponding to the drop of the carbon flame, to mark the end of the operation. Worst of all is the danger of excessive rephosphorization when the recarburizer is added; for rephosphorization always takes place to some extent, say as much as 0.02 per cent, and it may be three times as much if conditions are not just right. Finally, the composition of the slag must be kept constant so that it can be sold as a fertilizer. All these technical and practical problems were worked out in Germany long ago, and all successful basic Bessemer practice is a copy of what has been done on the banks of the Rhine.

Here in the United States we are apt to forget how important a part the basic converter plays in the steel industry. In 1913 it made nearly one-quarter of all the steel of the world, and almost as much as the acid
Bessemer and the acid open-hearth put together. During Bessemer and the acid open-hearth put together. During
the ten years from 1903 to 1913 the world's output the ten years from 1903 to 1913 the world's output
from the acid converter increased only 8 per cent, but the production from the basic vessel nearly doubled. A great part of this basic Bessemer steel comes from Belgium and from that portion of France which is in the war zone; so all figures for the last two years are worthless. But there is every reason to suppose that production will be resumed and will increase soon after the declaration of peace.

\section{Solvents of Coal}

THE author records extraction experiments with pyridine and quinoline on a series of coals, and results was powdered to pass a sieve of 900 meshes to the sq. dried in vacuo, and extracted with boiling pyridine in a Soxhlet apparatus. Generally a large apparatus of copper (silver-plated to prevent attack by pyridine) was used. Glass rods were placed in the basket carrying the charge prior to filling; on removing them the charge was oosened. Common salt or potassium sulphate was mixed with the coal to prevent caking during extraction Though unaffected by the pyridine, they could be extracted with water from the residue at the end. The xtract was concentrated by distillation in vacuo, and added to an excess of dilute hydrochloric acid which produced a brown precipitate. This was washed with water and dried in vacuo. The residue insoluble in pyridine was treated with water and hydrochloric acid and dried.

Generally speaking, the pyridine extract is large when the volatile matter is high, but there is no close parallelism. The volatile matter in the residue, compith the original coal, is also reduced, excepting cases where the extraction is slight. The small increase in such cases is probably accidental and due to coking properties or else none at all, but extract and residue mixed will still coke. The pyridine extracts are brown powders, insoluble in water, acids, and alkali, but partially soluble in organic solvents giving fluorescen solutions. The extract is soluble in fuming nitric acid, and if the extract be first suspended in glacial acetic acid, oxidation is minimized. The product, on precipita more combustible. The pyridine extract and also coals low in volatile matter, even anthracite, behrave similarly. The coal from Lens (mine 8) was also extracted with The coal from Lens (mine 8) was also extracted with
quinoline. The extract at $120^{\circ} \mathrm{C}$. was more than times greater than with pyridine at about the same temperature. At the boiling point of quinoline $\left(238^{\circ} \mathrm{C}\right.$. $)$ 5.56 per cent of the coal was extracted. At this temperature decomposition secmed to occur in addition to simple solution, for the residue had lost all coking propertics and these could not be restored by mixing the extract with the residue. Ultimate analyses of the pyridine extract and the original coal were almost identical. The hydrogen and nitrogen contents of the extract were higher in the former case, due perhaps to retention of solvent. The methods of metallographic analysis were applied to some of the samples. A polished specimen of coal from Lens (mine 8) which gives a small pyridine extract, showed no change of structure after etching with pyridine. A sample from mine 3 showed dark areas which became more marked after etching. A sample of coal from Prankenholtz (seam X), which showed a perfectly polished surface before attack, showed a perfectly polished surface before at
disclosed granular bands after pyridine extraction.

- Note in Journal of the Society of Industry in a paper by A. WAHL in Bull. Soc. Chem. 